\title{
DESEMPENHO OPERACIONAL DE UMA SEMEADORA-ADUBADORA DE PRECISÃO, EM FUNÇÃO DO PREPARO DO SOLO E DO MANEJO DA COBERTURA DE INVERNO ${ }^{1}$
}

\author{
CARLOS E. A. FURLANI ${ }^{2}$, CARLOS A. GAMERO ${ }^{3}$, RENATO LEVIEN ${ }^{4}$, AFONSO LOPES ${ }^{2}$, \\ ROUVERSON P. DA SILVA ${ }^{2}$
}

RESUMO: Avaliou-se o desempenho operacional de campo de uma semeadora-adubadora de precisão, equipada com seis linhas espaçadas de $550 \mathrm{~mm}$, em um solo muito argiloso, classificado como Nitossolo Vermelho Distrófico Latossólico, na semeadura do feijoeiro (Phaseolus vulgaris L.). Os tratamentos consistiram de três métodos de preparo do solo: a) convencional (uma aração com arado de discos e duas gradagens niveladoras); b) escarificação (uma passagem de escarificador conjugado com rolo destorroador), e c) semeadura direta. Esses procedimentos foram combinados com quatro condições de cobertura do solo no inverno (consórcio aveia-preta + nabo forrageiro manejados com rolo-faca, triturador de palhas, herbicida e solo em pousio). Os métodos de preparo do solo e os manejos da cobertura foram repetidos por três anos consecutivos. Os valores de força e pico de força de tração na barra, patinagem dos rodados motrizes e consumo de combustível foram maiores no preparo com escarificador em relação aos obtidos no preparo convencional e na semeadura direta. A capacidade de campo efetiva foi maior na semeadura direta em relação aos outros tratamentos. Os manejos efetuados nas coberturas vegetais e o solo mantido em pousio não influenciaram em nenhuma das variáveis.

PALAVRAS-CHAVE: força de tração, consumo de combustível, feijão.

\section{FIELD OPERATION PERFORMANCE OF A GRAIN DRILL IN FUNCTION OF TILLAGE SYSTEMS AND SOIL COVERING IN WINTER TIME}

SUMMARY: The field operation performance of a precision grain drill with six lines spaced of $550 \mathrm{~mm}$ was evaluated in a very loamy soil, classified as Nitossolo Vermelho Distrófico Latossólico for bean (Phaseolus vulgaris L.) seeding. The treatments consisted of three tillage systems: a) conventional (primary tillage plowing with disk plow and twice harrowing with tandem disk harrow); b) chiseling (tillage with chisel plow combined with roller, and c) no tillage. Those procedures were combined with four conditions of soil covering in winter time (consortium oat + turnip managed with cutting-roller, straw-crusher, herbicide and discovered soil). The tillage systems and the soil covering management were replicated on three consecutive years. The values of force and pick of traction force in the bar, skating of the wheeled and consumption of fuel were bigger in the chiseling tillage management related to the ones obtained in the conventional tillage and no tillage. The effective field capacity was bigger in no tillage system related to the other treatments. The management in the winter cover crop and the discovered soil didn't influence any one of the variables.

KEYWORDS: traction force, consumption of fuel, bean.

\footnotetext{
${ }^{1}$ Parte da tese de Doutorado apresentada pelo primeiro autor à Faculdade de Ciências Agronômicas, UNESP, Câmpus de Botucatu - SP.

${ }^{2}$ Prof. Dr., Departamento de Engenharia Rural, UNESP - Câmpus de Jaboticabal - SP, Via de Acesso Prof. Paulo Donato Castellane, s/n, e-mail: furlani@fcav.unesp.br

${ }^{3}$ Prof. Titular, Departamento de Engenharia Rural, FCA/UNESP, Botucatu - SP.

${ }^{4}$ Prof. Adjunto, Departamento de Solos, FA/UFRGS, Porto Alegre - RS.

Recebido pelo Conselho Editorial em: 4-9-2003

Aprovado pelo Conselho Editorial em: 5-5-2004
} 


\section{INTRODUÇÃO}

A escolha de um sistema de cultivo é complexa, mudando de região para região, tipo de solo, condições climáticas, entre outras. Assim, o método de preparo do solo e o sistema de manejo da cobertura vegetal tornam-se fatores importantes no auxílio da conservação do solo.

O sistema de semeadura direta está cada vez mais presente na agricultura brasileira. É um método que visa à maior conservação do solo e diminuição do tráfego de máquinas, tendo como princípio a semeadura diretamente em solo não-revolvido. Porém, hoje ainda se utiliza muito o preparo convencional, que normalmente é composto por uma aração com arado de disco, seguido de duas gradagens niveladoras, sendo extremamente importante a otimização desse sistema.

Intermediário aos dois sistemas anteriormente citados, aparece o chamado preparo reduzido que implica redução das operações de preparo do solo. Esse sistema já está bastante difundido no Brasil, sendo realizado por meio do uso de escarificadores, normalmente equipados com discos de corte na frente de cada haste, para trabalhos em solos com palha na superfície. Também acompanha o equipamento, regra geral, um rolo destorroador, que tem por função diminuir o tamanho dos torrões e nivelar o solo para a semeadura, tornando-se um equipamento conjugado, que realiza mais de uma operação em cada passagem.

O consumo de combustível de diversos tratores na operação de semeadura foi estudado durante quatro anos por CORDEIRO et al. (1988). Os valores médios encontrados para um trator de potência no motor de 82,4 $\mathrm{kW}(110 \mathrm{cv})$ foi de 8,5 litros por hora. LEVIEN et al. (1999) obtiveram valores de 13,0; 12,9 e 12,3 litros por hora de óleo diesel para semeadura em solo classificado como Nitossolo Vermelho Distrófico Latossólico, preparado pelo método convencional, reduzido (escarificação) e plantio direto, respectivamente. A força de tração para semeadoras de precisão varia em função do tipo de solo, leito de semeadura e número de linhas. Para solos argilosos, os valores variam de 1,10 a 2,00 kN por linha de semeadura da máquina (ASAE, 1996).

LEVIEN et al. (1999) encontraram valores de força de tração de 3,24 a 3,64 kN por linha de semeadura, não diferindo estatisticamente entre os tratamentos de preparo do solo (convencional, escarificação e semeadura direta). Os mesmos autores encontraram, ainda, que a necessidade de potência na barra para a operação de semeadura foi de $19,9(26,5) ; 21,4(28,5)$ e $23,7(31,6) \mathrm{kW}$ (cv) para o preparos do solo convencional, escarificação e no sistema de plantio direto, respectivamente. CHAPLIN et al. (1988) relataram que a semeadora (quatro linhas) para plantio direto necessitou de $3,3 \mathrm{kN}$ de força de tração; 7,5 kW (10,0 cv) de potência na barra; $6,6 \mathrm{~L} \mathrm{ha}^{-1}$ de consumo de óleo diesel; $2,5 \mathrm{ha} \mathrm{h}^{-1}$ de capacidade de campo teórica, e 3,0 $\mathrm{kWh} \mathrm{ha}^{-1}$ de consumo de energia, enquanto a semeadora, operando em solo preparado, utilizou $1,9 \mathrm{kN} ; 5,1 \mathrm{~kW}(6,8 \mathrm{cv}) ; 6,8 \mathrm{~L} \mathrm{~h}^{-1} ; 2,9 \mathrm{ha} \mathrm{h}^{-1}$, e $1,7 \mathrm{kWh} \mathrm{ha}^{-1}$.

A ASAE (1989) recomenda, para a obtenção de máxima eficiência de tração, patinagem de 8 $10 \%$ em solos não mobilizados e de 11 a $13 \%$ em solos mobilizados.

O objetivo do presente trabalho foi avaliar o desempenho operacional de uma semeadoraadubadora de precisão, em três sistemas de preparo do solo (convencional, escarificação e plantio direto), combinados com quatro manejos da cobertura de inverno (rolo-faca, triturador de palhas tratorizado, herbicida e solo sob pousio) na semeadura de feijão.

\section{MATERIAL E MÉTODOS}

O experimento foi instalado e conduzido em área da Fazenda Experimental Lageado, pertencente à Faculdade de Ciências Agronômicas - UNESP - Câmpus de Botucatu - SP, localizado nas coordenadas geográficas $22^{\circ} 49^{\prime}$ Latitude Sul e $48^{\circ} 25^{\prime}$ Longitude Oeste, com altitude média de $770 \mathrm{~m}$ e declividade variável de 0 a $3 \%$. O solo da área do experimento foi classificado por 
CARVALHO et al. (1983) como Terra Roxa Estruturada Distrófica, Unidade Lageado, textura muito argilosa, apresentando boa drenagem e, atualmente, como Nitossolo Vermelho Distrófico Latossólico (EMBRAPA, 1999).

Na semeadura, empregaram-se $60 \mathrm{~kg} \mathrm{ha}^{-1}$ de feijão (Phaseolus vulgaris L.), cv. IAC-Carioca, com poder germinativo de $87 \%$ e pureza de $99 \%$.

Para a realização das operações de preparo do solo (aração, gradagens e escarificação), manejo das coberturas de inverno com rolo-faca e triturador de palhas, e semeadura da cultura do feijão, foi utilizado um trator marca Valmet, modelo $128-4$ com potência de $90,5 \mathrm{~kW}(123,1 \mathrm{cv})$ no motor e, para a operação de pulverização, um trator marca Ford New Holland, modelo 3030, com potência de $38,5 \mathrm{~kW}(52,4 \mathrm{cv})$ no motor. Os implementos utilizados nessas operações foram: um arado reversível, marca Jan, modelo AR-430, montado, de quatro discos com diâmetro de 760 mm (30"); um escarificador marca Jan, modelo Jumbo Matic JMHD-7, de arrasto, com sete hastes parabólicas espaçadas a $334 \mathrm{~mm}$, equipado com rolo destorroador e discos de corte; uma grade niveladora excêntrica marca Tatu, modelo GNL 32, de arrasto, com 32 discos de 508 mm de diâmetro (20"); um triturador de restos culturais, marca Jan, modelo Tritton 2300, montado, um rolo-faca de arrasto marca Dobruski, modelo D 2000, com dois rolos em tandem com $610 \mathrm{~mm}$ de diâmetro e largura de 2,010 m, pesando $750 \mathrm{~kg}$ cada; um pulverizador de barras marca Jacto, modelo PJ-600, montado, e uma semeadora-adubadora de precisão de arrasto, marca Tatu, modelo PST2, com seis linhas espaçadas de $550 \mathrm{~mm}$, sulcadores do tipo haste escarificadora, reservatório de sementes e de fertilizantes com capacidade de $40 \mathrm{~kg}$ por linha e $725 \mathrm{~kg}$, respectivamente.

Avaliou-se o teor de água no solo antes da semeadura, utilizando o método gravimétrico padrão, conforme EMBRAPA (1979). A porcentagem de cobertura do solo por resíduos vegetais foi obtida seguindo metodologia de LAFLEN et al. (1981). A força na barra de tração, a patinagem dos rodados motrizes e o tempo de percurso nas parcelas foram determinados com equipamento construído e descrito por SILVA (1997). A força de tração por linha da semeadora foi obtida pela divisão da força de tração na barra pelo número de linhas da semeadora. O consumo de combustível foi determinado utilizando-se de equipamento construído e descrito por GAMERO et al. (1986). A capacidade de campo efetiva da semeadora-adubadora foi calculada pela eq.(1):

$$
\mathrm{Cc}=\mathrm{Lt} \mathrm{V} \quad 0,36
$$

em que,

Cc - capacidade de campo da semeadora-adubadora, ha $\mathrm{h}^{-1}$;

$\mathrm{Lt}$ - largura da faixa trabalhada pelo equipamento, m;

$\mathrm{V}$ - velocidade de deslocamento do conjunto trator-semeadora, $\mathrm{m} \mathrm{s}^{-1}$, e

0,36 - fator de conversão de unidades para expressar o resultado em ha $\mathrm{h}^{-1}$.

A potência demandada na barra de tração do trator na operação de semeadura foi obtida pela eq.(2):

$$
\mathrm{P}=\mathrm{Ft} \mathrm{V} \quad 0,0098096
$$

em que,

$\mathrm{P}$ - potência na barra de tração, $\mathrm{kW}$;

Ft - força de tração, kgf;

$\mathrm{V}$ - velocidade de deslocamento do conjunto trator-semeadora, $\mathrm{m} \mathrm{s}^{-1}$, e

0,0098096 - fator de conversão de unidades para expressar o resultado em kW.

O consumo de energia na operação de semeadura foi obtido pela eq.(3):

$\mathrm{Ce}=\mathrm{P} \mathrm{Cc}^{-1}$ 
em que,

Ce - consumo de energia, $\mathrm{kWh} \mathrm{ha}^{-1}$;

$\mathrm{P}$ - potência, $\mathrm{kW}$, e

Cc- capacidade de campo efetiva, ha $\mathrm{h}^{-1}$.

\section{RESULTADOS E DISCUSSÃO}

$\mathrm{Na}$ Tabela 1, são apresentados os valores do teor de água e a porcentagem de cobertura do solo após a operação de semeadura.

TABELA 1. Cobertura do solo e teor de água nas camadas de solo de 0 a 10 e de 10 a $20 \mathrm{~cm}$ de profundidade $\left(\mathrm{g} \mathrm{kg}^{-1}\right)$ no dia da semeadura da cultura do feijoeiro, para os diferentes preparos do solo e manejos de cobertura.

\begin{tabular}{lccc}
\hline Fatores & \multicolumn{2}{c}{ Teor de Água $\left(\mathrm{g} \mathrm{kg}^{-1}\right)$} & Cobertura \\
\hline Preparos (P) & $0-10 \mathrm{~cm}$ & $10-20 \mathrm{~cm}$ & $(\%)$ \\
\hline Plantio direto & $287,8 \mathrm{a}$ & $297,8 \mathrm{~b}$ & 76 \\
Escarificação & $310,2 \mathrm{a}$ & $324,2 \mathrm{a}$ & 37 \\
Convencional & $307,8 \mathrm{a}$ & $322,9 \mathrm{a}$ & 8 \\
\hline Manejos (M) & & & 46 \\
\hline Rolo-faca & $295,6 \mathrm{a}$ & $313,4 \mathrm{a}$ & 45 \\
Triturador & $301,9 \mathrm{a}$ & $312,6 \mathrm{a}$ & 46 \\
Herbicida & $310,4 \mathrm{a}$ & $311,7 \mathrm{a}$ & 25 \\
Pousio & $299,8 \mathrm{a}$ & $322,1 \mathrm{a}$ & \\
\hline Teste F & & & $678,6797^{*}$ \\
\hline P & $2,0954 \mathrm{~ns}$ & $13,0584^{*}$ & $75,4740^{*}$ \\
M & $0,4040 \mathrm{~ns}$ & $1,0071 \mathrm{~ns}$ & $7,4383^{*}$ \\
P x M & $0,8449 \mathrm{~ns}$ & $2,2317 \mathrm{~ns}$ & 12,92 \\
\hline C.V. $(\%)$ & 11,3 & 5,2 &
\end{tabular}

O teor de água no dia da semeadura da cultura do feijoeiro não apresentou diferença significativa na camada de 0 a $10 \mathrm{~cm}$ de profundidade entre os diferentes tipos de preparo do solo. Na camada de 10 a $20 \mathrm{~cm}$, a semeadura direta apresentou menor teor de água, quando comparada aos preparos com escarificador e convencional. Nos diferentes manejos das coberturas de inverno, não houve diferença significativa. Como os mecanismos rompedores de solo da semeadora atuaram praticamente nos primeiros $10 \mathrm{~cm}$ do solo, pode-se considerar que o teor de água não interferiu nos parâmetros analisados.

A porcentagem de cobertura do solo por resíduos vegetais apresentou interação significativa. $\mathrm{Na}$ Tabela 2, apresentam-se os valores do desdobramento dessa variável.

Na Tabela 2, evidencia-se que, no sistema de plantio direto, após a semeadura, permaneceram na superfície do solo mais de $60 \%$ de cobertura, sendo maior que na escarificação e no preparo convencional, respectivamente. Tanto o plantio direto quanto a escarificação (exceção feita ao manejo pousio) são considerados sistemas conservacionistas, segundo a ASAE (1982), que preconiza uma cobertura do solo superior a 30\% de resíduos após a semeadura. 
TABELA 2. Interação entre os fatores preparo do solo e manejo da cobertura vegetal para a variável cobertura do solo por resíduos vegetais após a operação de semeadura.

\begin{tabular}{lccr}
\hline \multirow{2}{*}{ Manejos } & & Preparos & \\
\cline { 2 - 4 } & Plantio direto & Escarificação & Convencional \\
\hline Rolo-faca & 78 a A & 50 a B & 11 a C \\
Triturador & 80 a A & 45 a B & 9 a C \\
Herbicida & 85 a A & 41 a B & 12 a C \\
Pousio & $62 \mathrm{~b} \mathrm{~A}$ & $12 \mathrm{~b} \mathrm{~B}$ & 2 a C \\
\hline
\end{tabular}

Em cada coluna, para cada fator, médias seguidas de mesma letra minúscula, e em cada linha, médias seguidas de mesma letra maiúscula não diferem entre si, pelo Teste de Tukey, a 5\% de probabilidade.

Na Tabela 3, verifica-se que, na operação de semeadura, os tratamentos com semeadura direta e preparo convencional apresentaram menor força de tração, com diferenças significativas em relação ao tratamento com escarificador. Quando o solo foi preparado com escarificador, essa força foi $22 \%$ maior em relação aos demais tratamentos. O tipo de manejo do solo não apresentou diferenças significativas. O pico de força de tração na barra apresentou o mesmo comportamento que a força de tração, porém, no solo preparado com escarificador, a exigência foi próxima a 8\% superior aos demais. A força de tração exigida por linha de semeadura também foi maior em solo preparado com escarificador; esses dados estão bem próximos aos preconizados pela ASAE (1996) e ainda inferiores aos encontrados por LEVIEN et al. (1999).

TABELA 3. Força de tração na barra durante a operação de semeadura.

\begin{tabular}{lccc}
\hline Fatores & Força de Tração Média & Força de Tração por Linha & Pico de Força \\
\hline Preparos $(\mathrm{P})$ & $(\mathrm{kN})$ & $\left(\mathrm{kN} \mathrm{linha}{ }^{-1}\right)$ & $(\mathrm{kN})$ \\
\hline Plantio direto & $12,87 \mathrm{~b}$ & $2,15 \mathrm{~b}$ & $16,70 \mathrm{~b}$ \\
Escarificação & $14,52 \mathrm{a}$ & $2,42 \mathrm{a}$ & $17,83 \mathrm{a}$ \\
Convencional & $12,99 \mathrm{~b}$ & $2,17 \mathrm{~b}$ & $16,14 \mathrm{~b}$ \\
\hline Manejos $(\mathrm{M})$ & & & $16,75 \mathrm{a}$ \\
\hline Rolo faca & $13,21 \mathrm{a}$ & $2,20 \mathrm{a}$ & $16,90 \mathrm{a}$ \\
Triturador & $13,47 \mathrm{a}$ & $2,25 \mathrm{a}$ & $16,96 \mathrm{a}$ \\
Herbicida & $13,51 \mathrm{a}$ & $2,25 \mathrm{a}$ & $16,94 \mathrm{a}$ \\
Pousio & $13,65 \mathrm{a}$ & $2,28 \mathrm{a}$ & $13,2204 *$ \\
\hline Teste F & & & $0,1199 \mathrm{~ns}$ \\
P & $45,5760 *$ & $45,5760 *$ & $0,2595 \mathrm{~ns}$ \\
M & $1,3905 \mathrm{~ns}$ & $1,3905 \mathrm{~ns}$ & 5,6 \\
P x M & $0,9835 \mathrm{~ns}$ & $0,9835 \mathrm{~ns}$ & 4,1 \\
\hline C.V. $(\%)$ & 4,1 & &
\end{tabular}

O manejo das coberturas de inverno não influenciou estatisticamente na exigência de potência na barra da tração (Tabela 4), porém, no preparo do solo com escarificador, essa foi maior, diferindo estatisticamente do preparo convencional, sendo que a semeadura direta ficou em posição intermediária, não diferindo dos outros dois tratamentos. Os valores de potência obtidos são inferiores àqueles encontrados por LEVIEN et al. (1999). A potência exigida por linha de semeadura foi maior em solo escarificado e menor no preparo convencional.

O consumo de energia na operação de semeadura foi cerca de $13 \%$ maior no solo preparado com escarificador, em relação ao plantio direto e preparo convencional, enquanto os manejos da cobertura não influenciaram nesse parâmetro. 
A patinagem das rodas motrizes foi menor quando o trator trabalhou em solo não preparado, aumentando significativamente no preparo convencional; a maior patinagem ocorreu na operação de escarificação. Os valores para o plantio direto e preparo convencional estão abaixo dos recomendados pela ASAE (1989) e para a escarificação acima. Esse aumento nos valores obtidos de deslizamento foi, provavelmente, devido ao solo estar mais desagregado nos tratamentos de escarificação e convencional. A vegetação manejada não influenciou na patinagem, ou seja, o consórcio aveiapreta/nabo forrageiro somente acamado (rolo-faca), triturado (triturador), em pé (herbicida) e pousio não alteram a patinagem dos rodados motrizes do trator.

TABELA 4. Potência e potência por linha na barra de tração, consumo de energia e patinagem das rodas na operação de semeadura.

\begin{tabular}{|c|c|c|c|c|}
\hline Fatores & Potência Média & Potência por Linha & Consumo de Energia & Patinagem \\
\hline Preparos (P) & $(\mathrm{kW})$ & $\left(\mathrm{kW} \operatorname{linha}^{-1}\right)$ & $\left(\mathrm{kWh} \mathrm{ha}^{-1}\right)$ & $(\%)$ \\
\hline Plantio direto & $16,83 \mathrm{ab}$ & $2,80 \mathrm{ab}$ & $10,87 \mathrm{~b}$ & $6,25 \mathrm{c}$ \\
\hline Escarificação & $17,19 \mathrm{a}$ & $2,87 \mathrm{a}$ & $12,28 \mathrm{a}$ & $14,85 \mathrm{a}$ \\
\hline Convencional & $16,48 \mathrm{~b}$ & $2,75 \mathrm{~b}$ & $10,93 \mathrm{~b}$ & $9,39 \mathrm{~b}$ \\
\hline \multicolumn{5}{|l|}{ Manejos (M) } \\
\hline Rolo-faca & $16,58 \mathrm{a}$ & $2,76 \mathrm{a}$ & $11,15 \mathrm{a}$ & $9,75 \mathrm{a}$ \\
\hline Triturador & $16,79 \mathrm{a}$ & $2,80 \mathrm{a}$ & $11,41 \mathrm{a}$ & $10,47 \mathrm{a}$ \\
\hline Herbicida & $16,89 \mathrm{a}$ & $2,82 \mathrm{a}$ & $11,42 \mathrm{a}$ & $10,03 \mathrm{a}$ \\
\hline Pousio & $17,08 \mathrm{a}$ & $2,85 \mathrm{a}$ & $11,46 \mathrm{a}$ & $10,40 \mathrm{a}$ \\
\hline \multicolumn{5}{|l|}{ Teste F } \\
\hline$\overline{\mathrm{P}}$ & $5,5244^{*}$ & $5,5244 *$ & $49,5363^{*}$ & $173,5180 *$ \\
\hline M & $1,4429 \mathrm{~ns}$ & $1,4429 \mathrm{~ns}$ & $1,1781 \mathrm{~ns}$ & $0,7690 \mathrm{~ns}$ \\
\hline $\mathrm{P} \times \mathrm{M}$ & $1,7365 \mathrm{~ns}$ & $1,7365 \mathrm{~ns}$ & $0,9526 \mathrm{~ns}$ & $1,6846 \mathrm{~ns}$ \\
\hline C.V. (\%) & 3,57 & 3,57 & 3,97 & 13,00 \\
\hline
\end{tabular}

A capacidade de campo efetiva na operação de semeadura foi influenciada pela patinagem das rodas motrizes do trator (menor velocidade), em que o deslizamento foi maior, ou seja, na semeadura direta, a capacidade de campo foi maior. No solo preparado pelo método convencional e com escarificador, também foi encontrada diferença significativa. Verifica-se, portanto, que, quanto maior o grau de desagregação do solo obtido nos tratamentos de preparo, menor foi a capacidade de campo dos conjuntos motomecanizados. O manejo da cobertura do solo no inverno não influenciou na capacidade de campo efetiva da semeadora.

O consumo horário de combustível na operação de semeadura foi maior no preparo do solo com escarificador, sendo quase $2 \mathrm{~L}$ a mais em relação aos valores obtidos para a semeadura direta e o preparo convencional. Isso se deveu ao fato da maior rugosidade superficial e da maior profundidade da camada mobilizada apresentada por esse tratamento, uma vez que, estando o solo mais solto, foi exigido mais dos rodados do trator. Todos os valores de consumo horário de combustível foram superiores aos encontrados por CORDEIRO et al. (1988). O manejo da cobertura de inverno não apresentou diferença significativa entre os tratamentos, sendo resultados semelhantes também encontrados por LEVIEN et al. (1999).

O consumo de combustível por área trabalhada também foi maior no preparo com escarificador, e o preparo convencional apresentou diferença significativa em relação ao tratamento com semeadura direta, que apresentou o menor valor de consumo de combustível por hectare. Os valores obtidos para o manejo da cobertura não apresentaram diferenças significativas. 
TABELA 5. Consumo horário, consumo por área e capacidade de campo efetiva na operação de semeadura.

\begin{tabular}{lccc}
\hline Fatores & Consumo & Consumo & Capacidade de Campo Efetiva \\
\hline Preparos (P) & $\left(\mathrm{L} \mathrm{h}^{-1}\right)$ & $\left(\mathrm{L} \mathrm{ha}^{-1}\right)$ & $\left(\mathrm{ha} \mathrm{h}^{-1}\right)$ \\
\hline Plantio direto & $11,07 \mathrm{~b}$ & $7,13 \mathrm{c}$ & $1,55 \mathrm{a}$ \\
Escarificação & $13,04 \mathrm{a}$ & $9,27 \mathrm{a}$ & $1,40 \mathrm{c}$ \\
Convencional & $11,40 \mathrm{~b}$ & $7,58 \mathrm{~b}$ & $1,51 \mathrm{~b}$ \\
\hline Manejos (M) & & & $1,49 \mathrm{a}$ \\
\hline Rolo-faca & $12,09 \mathrm{a}$ & $8,13 \mathrm{a}$ & $1,48 \mathrm{a}$ \\
Triturador & $11,76 \mathrm{a}$ & $7,98 \mathrm{a}$ & $1,48 \mathrm{a}$ \\
Herbicida & $11,83 \mathrm{a}$ & $7,99 \mathrm{a}$ & $1,49 \mathrm{a}$ \\
Pousio & $11,66 \mathrm{a}$ & $7,88 \mathrm{a}$ & \\
\hline Teste F & & & $0,8345 \mathrm{~ns}$ \\
P & $41,7578 *$ & $99,6962 *$ & $1,7448 \mathrm{~ns}$ \\
M & $0,9674 \mathrm{~ns}$ & $0,5844 \mathrm{~ns}$ & 2,04 \\
P x M & $1,1582 \mathrm{~ns}$ & $2,1331 \mathrm{~ns}$ & \\
\hline C.V. $(\%)$ & 5,51 & 5,65 &
\end{tabular}

\section{CONCLUSÕES}

A exigência de força de tração foi maior em solo preparado com escarificador em relação ao plantio direto e preparo convencional. Para a potência, em solo escarificado, a demanda foi maior em relação ao convencional, e o plantio direto ficou em posição intermediária.

No preparo de solo com escarificador, o consumo de energia e o consumo horário de combustível foram maiores em relação ao convencional e ao plantio direto; o inverso ocorreu com a capacidade de campo efetiva. A patinagem e o consumo por área foram aumentando do plantio direto para o convencional e, por último, para a escarificação.

\section{REFERÊNCIAS BIBLIOGRÁFICAS}

AMERICAN SOCIETY OF AGRICULTURAL ENGINEERS. Terminology and definitions for soil tillage and soil tool relationships. In: ASAE standards 1982: standards engineering practices data. St. Joseph, 1982. p. 229-41. (ASAE EP291.1).

AMERICAN SOCIETY OF AGRICULTURAL ENGINEERS. Agricultural tractor test code. In: ASAE standards 1989: standards engineering practices data. St. Joseph, 1989. p.44-8. (ASAE S209.5) AMERICAN SOCIETY OF AGRICULTURAL ENGINEERS. Agricultural Machinery Management Data. In: ASAE standards 1996: standards engineering practices data. St. Joseph, 1996. p. 332-9. (ASAE D-497.2).

CARVALHO, W.A.; ESPÍNDOLA, C.R.; PACCOLA, A.A. Levantamento de solos da Fazenda Lageado - Estação Experimental "Presidente Médici". Boletim Científico da Faculdade de Ciências Agronômicas da UNESP, Botucatu, n.1, p.1-85, 1983.

CHAPLIN, J.; JENANE, C.; LUEDERS, M. Drawbar energy use for tillage operations on Loamy sand. Transactions of the ASAE, St. Joseph, v.31, p.1692-4, 1988.

CORDEIRO, M.A.L.; BENEZ, S.H.; SOUSA, A.P. Consumo de combustível em tratores agrícolas trabalhando com semeadoras adubadoras e com pulverizadores. In: CONGRESSO BRASILEIRO DE ENGENHARIA AGRÍCOLA, 17., 1988, Iperó. Anais... Sorocaba: Sociedade Brasileira de Engenharia Agrícola, 1988. p.339-49. 
EMPRESA BRASILEIRA DE PESQUISA AGROPECUÁRIA. Serviço Nacional de Levantamento e Conservação do Solo. Manual de métodos de análise de solo. Rio de Janeiro, 1979. Parte 1, não paginado.

EMPRESA BRASILEIRA DE PESQUISA AGROPECUÁRIA. Centro Nacional de Pesquisa de Solos. Sistema brasileiro de classificação de solos. Brasília, 1999. 412 p.

GAMERO, C.A.; BENEZ, S.H.; FURLANI JÚNIOR, J.A. Análise do consumo de combustível e da capacidade de campo de diferentes sistemas de preparo periódico do solo. In: CONGRESSO BRASILEIRO DE ENGENHARIA AGRÍCOLA, 15., 1986, São Paulo. Anais... Botucatu: Sociedade Brasileira de Engenharia Agrícola, 1986. p.1-9.

LAFLEN, J.M.; AMEMIYA, A.; HINTZ, E.A. Measuring crop residue cover. Soil and Water Conservation, Washington, 1981, v.36, n.6, p.341-3.

LEVIEN, R.; MARQUES, J.P.; BENEZ, S.H. Desempenho de uma semeadora adubadora de precisão, em semeadura de milho (Zea mays L.), sob diferentes formas de manejo do solo. In: CONGRESSO BRASILEIRO DE ENGENHARIA AGRÍCOLA, 28., 1999, Pelotas. Anais... Pelotas: Sociedade Brasileira de Engenharia Agrícola, 1999. 1 CD ROM.

SILVA, S.L. Projeto e construção de sistema de aquisição de dados para avaliação do desempenho energético de máquinas e implementos agrícolas. 1997. 148 f. Dissertação (Mestrado em Energia na Agricultura) - Faculdade de Ciências Agronômicas, Universidade Estadual Paulista, Botucatu, 1997. 